\section{Methylation makes} the brain female

Normal development of the female rat brain requires active silencing of key maleassociated genes during a critical period just before and after birth.

Bridget Nugent at the University of Maryland School of Medicine in Baltimore and her colleagues studied a region of the rat brain that differs significantly in males and females. They found that in females shortly after birth, there were more methyl groups attached to DNA in this brain region, reducing gene expression.

When they injected newborn females with a male hormone, the activity of an enzyme that adds methyl groups to DNA decreased. When they blocked the activity of this enzyme in female rats during the critical period after birth, the animals showed male-like gene expression and sexual behaviour.

Nature Neurosci. http://dx.doi. org/10.1038/nn.3988 (2015)

\section{CONSERVATION}

\section{More bang for the conservation buck}

Conservation money directed at charismatic species could be used more effectively to save animals if it was applied in a more scientific manner.

Joseph Bennett at the University of Queensland in Brisbane, Australia, and his colleagues modelled the impact of more than NZ\$1 million (US\$765,000) in private funding given to protect 10 iconic bird species

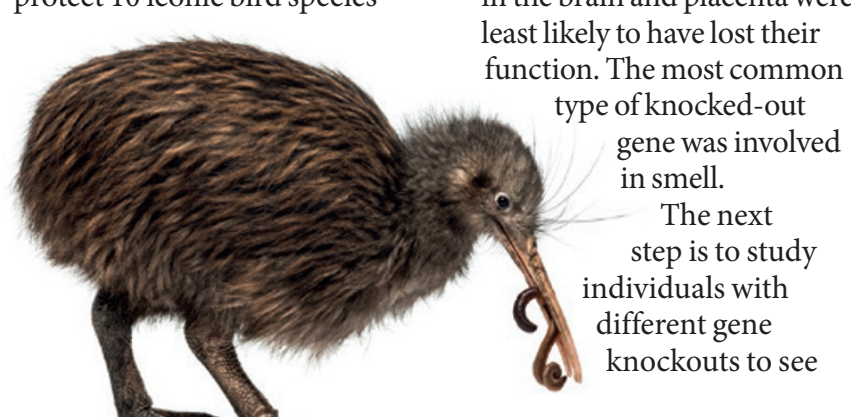

in New Zealand, including the North Island brown kiwi (Apteryx mantelli; pictured).

If funding was directed at only the 10 species as originally assigned, an average of 1.4 further species would be effectively conserved, compared to a scenario in which there was no private funding. If the money was allocated in a way that benefited other endangered animals as well as the 10 flagship species, 2.8 extra species on average could be conserved. If the money was spread more widely to non-iconic but birds, an average of 3.3 more species could be saved.

Although private funding for such flagship species can generate vital conservation revenue, it should be spent carefully to maximize conservation benefits, the authors say.

Proc. R. Soc. B 282, 20142693 (2015)

$$
\text { HUMAN GENETICS }
$$

\section{Iceland genomes reveal knockouts}

More than 8,000 Icelanders carry a gene that is completely inactivated by mutations.

Patrick Sulem, Kari

Stefansson and their colleagues at deCODE Genetics in Reykjavik sequenced the genomes of more than 2,600 Icelanders and used this to infer the genetics of another set of more than 100,000 people from Iceland. They found that $7.7 \%$ of this second set have low-frequency mutations that knock out both copies of at least one gene from a collection of almost 1,200 genes. Genes expressed in the brain and placenta were least likely to have lost their ction. The most common gene was involved smell.

The next step is to study different gene still-threatened New Zealand

\title{
SOCIAL SELECTION pomilumatices
}

\section{Call for open-source health data}

Open Humans, an online portal that encourages US citizens to share their DNA and other medical data with researchers, launched on 24 March. The announcement sparked discussion on social media that reflected both excitement and concerns over privacy. The website, run by New York University, the University of California in San Diego and Harvard Medical School in Boston, Massachusetts, is recruiting volunteers to provide personal health information for three research studies, with others potentially on the way. 'American gut' examines human gut microbiota, 'GoViral' profiles respiratory viruses, and the 'Harvard Personal Genome Project' collects genomic data. As Madeleine Ball, a geneticist at Harvard who is the principal investigator, wrote on Twitter: "Open source yourself to accelerate scientific discovery." Although some applauded the launch, others had reservations. "Putting \#opensource to

$\rightarrow$ NATURE.COM

For more on

popular papers:

go.nature.com/bbebfq the ultimate test. Where do individuals draw the line btwn privacy \& progress?" tweeted Ross Whippo, a marine ecologist at the Smithsonian Environmental Research Center in Edgewater, Maryland. what effects, if any, these mutations have on physiology and health.

Nature Genet. http://dx.doi. org/10.1038/ng.3243 (2015)

\section{CLIMATE CHANGE}

\section{Ice shelves shrink fast in Antarctica}

The floating parts of

Antarcticas ice sheets have

been thinning at increasing rates since the mid-1990s, raising fears of ice-sheet collapse and of accelerating sea-level rise in a warming climate.

Fernando Paolo of the Scripps Institution of Oceanography in San Diego, California, and his colleagues analysed an 18-year record of observations from three satellite radar missions. They found that the loss of ice-shelf volume increased from about 25 cubic kilometres a year in 1994-2003 to more than 300 cubic kilometres each year in 2003-2012.

This thinning has been most drastic in West Antarctica, where some floating shelves have lost almost one-fifth of their thickness in 18 years. If they continue to thin at current rates, these ice shelves will completely disappear within a century.

Science http://doi.org/278 (2015)

\section{ASTROPHYSICS}

\section{Zapped plasma emits sounds}

Sound waves could be ringing across the surfaces of stars.

A team led by Ravindra

Kumar of the Tata Institute of Fundamental Research in Mumbai, India, zapped a hot, dense cloud of plasma with an ultrafast laser and found that the rapid heating of the plasma generated acoustic oscillations with a frequency of roughly one trillion cycles per second.

The authors say that the plasma within stars could also be bunching up in such waves, as a natural consequence of the way plasma flows.

Phys. Rev. Lett. 115, 115001 (2015)

\section{DNATURE.COM}

For the latest research published by Naturevisit:

www.nature.com/latestresearch 